\title{
ASPECTOS SOCIOCULTURALES QUE DELIMITAN LAS DIFERENCIAS ENTRE LOS SISTEMAS ETNOMÉDICOS DE CHAMULA, CHENALHÓ Y OXCHUC EN EL ESTADO DE CHIAPAS
}

\author{
Jaime Tomás Page Pliego \\ jaimepagepliego@comunidad.unam.mx \\ Proimmse-IIA \\ Universidad Nacional Autónoma de México
}

\section{RESUMEN}

Diversos son los factores que en el mediano y corto plazo han incidido en la trasformación de los sistemas etnomédicos de la región Altos de Chiapas, en que destacan formas cambiantes de reproducción social y económica de la población maya en respuesta a la creciente pobreza, incidencia pertinaz de grupos religiosos, conflictividad política, y migración. En los tres casos que se presentan el devenir ha sido diferente, en función de las cargas diferenciadas de los elementos antes señalados. En el caso de Oxchuc se puede prácticamente hablar del surgimiento de un sistema de atención con abundantes elementos de diagnóstico biomédico y centrado en una atención a la enfermedad con base en la herbolaria medicinal. En los casos de Chamula y Chenalhó la presencia significativa de un sistema etnomédico fundamentado en el ritual que, si bien en las últimas décadas ha sufrido trasformaciones importantes, predomina aún por encima de los de otro corte. El presente artículo pretende delinear los aspectos socioculturales que delimitan las diferencias entre los casos.

Palabras clave: etnomedicina, cambio sociocultural. 


\section{ABSTRACT}

There are diverse factors that have affected the transformations taking place in the short and medium term in the ethnomedical systems in the Los Altos region of Chiapas. Those especially worth noting are the changing forms of social and economic reproduction in the Mayan population, in response to increasing poverty; the persistent impact by religious groups; a politically conflictive climate; and migration. The process of change has varied in the three cases presented, depending on the differentiated impact from the elements identified. In the case of Oxchuc we can practically speak of the emergence of a system in which there are abundant elements of biomedical diagnostics and a focus on using medicinal herbology to address illness. In the case of Chamula and Chenalhó it is important to note that an ethnomedical system centered on ritual continues to predominate over other systems, although it has experienced significant transformations in recent decades. The purpose of this article is to define the sociocultural aspects that mark the differences among the cases presented.

Key words: ethnomedicine, sociocultural change. 


\section{INTRODUCCIÓN}

La perspectiva histórica resulta fundamental para entender la ocurrencia de patrones diferentes de cambio en los tres municipios que nos ocupan, Chamula y Chenalhó cuyos habitantes hablan tsotsil, y Oxchuc en que se habla tseltal, motivo por el cual en primer término se presenta un esbozo de lo acaecido en su devenir, centrando los hechos ocurridos en cada municipio desde la década de 1930, debido a que durante este lapso se producen enormes cambios en las formas de concebir y vivir de estos grupos.

Los procesos socioculturales y religiosos que tienen lugar entre los diferentes pueblos mayas de Los Altos de Chiapas están marcados por la colonización española acaecida en el siglo XVI, así como por devenires históricos particulares inherentes a cada conglomerado humano. En la colonia temprana, destaca la conformación de «pueblos de indios» con familias provenientes de diferentes grupos mayas de la geografía chiapaneca, que tuvo como fin romper los fundamentos socioculturales, identitarios, históricos y organizativos prehispánicos, y con ello establecer mecanismos de control social firmes de la población maya hablante, neutralizar sus resistencias y facilitar la expoliación.

Sin embargo, a pesar del embate colonial, las poblaciones originarias de Los Altos de Chiapas lograron conservar elementos de su identidad prehispánica como producto, por un lado, de la resistencia de estos pueblos al colonialismo y, por otro, la conveniencia de la sociedad mestiza que los circunda por mantener a dicha población sin cambios, en aras de sostener el statu quo y perpetuar los mecanismos tradicionales de exacción.

La mayoría de estos pueblos —Chamula, Chenalhó, San Andrés, Cancuc, Huixtán, Oxchuc, Yajalón, etcétera- lograron a través de la organización social y religiosa preservar un cúmulo considerable de elementos prehispánicos en sus culturas. Lo antes expresado ha sido documentado suficientemente por un número considerable de investigadores sociales, entre los que destacan Holland 1963; Guiteras 1965; Hermitte 1970; Fábrega 1973; Favre 1973; Pozas 1977; Gossen 1980; Rus 1982, 1995; Ruz 1982; 
Villa Rojas 1990; Harman 1990; Medina 1991, 2000; Köhler 1995; Pitarch 1996, y Page 2005, entre los principales.

Después de varios siglos de cambios socioculturales no significativos, a partir de la década de 1930 delinean los elementos de orden sociocultural, religioso, económico y político que generarán cambios muy rápidos en las formas de concebir y vivir el mundo de los grupos señalados, cambios que se suscitan a diferente ritmo y profundidad, así como con particularidades específicas entre los diferentes pueblos, cada cual con un devenir histórico específico en función del interés o desinterés por parte de la población mestiza por los distintos recursos, incluyendo el humano con que cada cual contaba.

De entre los casos que nos ocupan, Chamula y Oxchuc se caracterizan por la pobre vocación productiva de la tierra, sumado a esto en Oxchuc se sufre de carencia de agua durante la época de secas. Por otro lado, Chenalhó resulta ser altamente productivo y con recursos hídricos vastos, lo que causó demanda mestiza por la tierra y despojo de la misma a la población originaria, así como su cooptación para el trabajo.

Si se habla de los hechos suscitados hacia la década de 1930, encontramos que como parte de la política agraria implementada por el gobierno encabezado por Lázaro Cárdenas, en 1935 se funda en San Cristóbal de Las Casas el Departamento de Acción Social, Cultural y de Protección al Indígena, DASCPI, y en 1936 el Sindicato de Trabajadores Indígenas (Favre 1973: 74). El discurso del Estado mexicano respecto de estas instituciones justifica la creación de las mismas, argumentando su necesidad a partir de la urgencia de frenar abusos de enganchadores, introducir la educación formal y sustituir a las autoridades ladinas que controlaban los municipios por jóvenes indígenas bilingües y alfabetizados (Robledo 1987: 69-70). Pero en realidad constituyó una acción más dentro de la estrategia integracionista —a lo que se aúna la instalación de profesores hablantes de maya, pero instalados en comunidades de lengua diferente, etc.- encaminada a desmantelar el tradicionalismo, colocando en las instancias de gobierno a jóvenes mayas educados en el contexto nacional. 
Parte de esta estrategia consistió en fortalecer económica y políticamente los diferentes grupos de jóvenes que fueron cuidadosamente seleccionados, en términos de su vocación «pro nacional», quienes fueron nombrados con cargos de presidente municipal y secretario en los municipios mayas alteños, y que posteriormente conformaron cacicazgos que hasta la fecha dejan sentir su poder en los diferentes municipios. Se hace mención de estos personajes y grupos porque han jugado un papel crucial en los cambios acaecidos durante las ocho últimas décadas.

En seguida se presentan particularidades de los tres municipios en cuestión, que fungen como catalizadores iniciales de los cambios que tuvieron lugar entre la década de 1970 y la actualidad.

\section{CHAMULA}

Chamula, se caracteriza por una baja productividad agrícola, por lo que desde la Colonia fue destinado a lo que se denominó «producción de mano de obra»:

... la comunidad fue rehecha después de la conquista, vuelta a congregar y refuncionalizada como proveedora de trabajo superfluo en tributo, especie y trabajo simple. Su economía natural básica, y las formas culturales que la acompañan — propiedad y usufructo común del suelo, relaciones más o menos igualitarias en el interior, escasa división social del trabajo, vida patriarcal, complejidad parental y clánica, etcétera - no fueron sin embargo sensiblemente destruidas, a pesar de que las comunidades se vieron reubicadas en su relación exterior, y de que el sistema Colonial introdujo nuevos valores ideológicos y económicos en su seno (García de León 1985: 122).

Como muestra la cita anterior, los habitantes de Chamula no fueron objeto de despojo de tierras ni tuvieron que sufrir la presencia mestiza; las formas de exacción eran principalmente la explotación de la fuerza de trabajo, que periódicamente se requería para la cosecha en las fincas de tierra caliente, así como la jardinería y construcción en San Cristóbal; y en segundo término el despojo o el pago irrisorio de verdura, animales de corral y artesanía. 
Otro pueblo que tuvo un devenir en el que destaca la ausencia mestiza es San Juan Cancuc, que a base de resistencia beligerante hasta la fecha ha logrado permanecer libre de su presencia. Estos dos pueblos lograron conformar sistemas sociales en los que la mano colonial actuó de manera indirecta y que, a diferencia de los demás pueblos de la Región Altos de Chiapas, hasta la fecha se han caracterizado por la presencia de mayor cantidad de elementos prehispánicos en sus cosmovisiones, y en cuyo orden el ámbito de lo religioso ha tenido mayor preeminencia que el civil.

Chamula fue gobernado por ancianos prestigiosos hasta la década de 1930, en que se nombra, no sin problemas al interior del municipio, como secretario municipal, con el apoyo de DASCPI, al Sr. Salvador López Tuxum (ver Robledo 1987: 70-81), quien con a la vez el apoyo de Juan Gómez Oso y Salvador Sánchez Gómez, con el tiempo él y su grupo acceden primero a la presidencia municipal para luego penetrar la jerarquía religiosa hasta su cúspide (Rus 1995a: 261-262; Page 2005: 39-65). Lo obtenido se tradujo en el desplazamiento de los ancianos, que dificultaban el ejercicio del poder, y eventualmente en el surgimiento de uno de los cacicazgos más poderosos de Los Altos de Chiapas, mismo que aún hoy prevalece.

Si bien la jerarquía de ancianos que detentaba el poder en Chamula fue gradualmente sustituida o cooptada por los tuxumetik, el poder religioso no solo no fue reemplazado por el poder civil sino reforzado. Esto aun cuando Salvador Tuxum controlaba ambas instancias. Así, la jerarquía religiosa continuó como puntal de la estructura organizativa.

La preeminencia religiosa permitió perpetuar el control social que ya de antaño se ejercía sobre la población del municipio, que entre otras cosas prohibía el comercio a quien no había ejercido un cargo público o religioso. Con ello llegaron a monopolizar además las instancias económicas de mayor importancia: todas las bebidas alcohólicas y el refresco, el trasporte, el acaparamiento de la producción especialmente de maíz y frijol, asimismo fungir como intermediarios en la contratación de trabajadores para las fincas, etcétera. (Page op. cit.) 
De igual manera, el cacicazgo de los tuxumetik se constituyó como bastión ante el avance del protestantismo, persiguiendo a los conversos y haciendo uso de inusual violencia, lo que coadyuvó a la expulsión de enormes grupos de población que principalmente se asentaron en la periferia de San Cristóbal de Las Casas y en las orillas de la carretera San Cristóbal-Teopisca, de cuyos asentamientos el más importante es el de Betania, incluso en conformación de nuevos poblados en la selva del municipio Las Margaritas.

Un elemento fundamental en la dinámica social proveniente de épocas previas a la instalación de los tuxumetik en el poder es el papel que ha jugado la etnomedicina ${ }^{1}$ en el control social. En este sentido, la etnomedicina ha fungido como reguladora de los códigos éticos y morales presentes en el grupo, y como tal media en la conflictividad social y coadyuva al sometimiento a las normas sociales impuestas en nombre de la costumbre. Entre otras, una forma de detectar a quienes se han convertido es que ante la enfermedad o cualquier otro infortunio no recurren en primera instancia en busca de atención o ayuda ante los j'iloletik - los que pueden ver-sentir-, captan la atención social y se convierten en sujetos que por atentar contra la costumbre han sido objeto de violencia y expulsión (ver Page 2005: 39-65).

\section{CHENALHÓ}

Otro de los pueblos que nos ocupa es San Pedro Chenalhó, municipio de terrenos productivos y, por ello, históricamente plagado de casos de despojo hacia los tsotsiles, así como de problemas para el reparto de la tierra después de la reforma agraria; también de sometimiento de la fuerza de trabajo, tanto para su explotación en la región como en las fincas de tierra caliente, lo cual se refleja en el hecho de que hasta mediados de la década de 1930 la mayor parte de la población tsotsil de Chenalhó estaba sujeta al baldiaje ${ }^{2}$ (Garza 1999: 61). Y algo que resulta de particular importancia para el devenir del ámbito de lo religioso es que la resolución de conflictos se ha dado desde antaño sobre la base de la legalidad nacional, a partir de lo cual se conformaron mecanismos sociales en donde si bien la religiosidad era de suma importancia, por efecto de la presencia mestiza, fue impuesta la instancia civil; es decir, la legalidad 
«nacional» para dirimir la conflictividad social, situándose el ámbito de lo religioso y concomitantemente el sistema etnomédico ${ }^{3}$ en un plano secundario.

En Chenalhó siempre ha tenido preeminencia el poder civil sobre el religioso. Debido a la labor desarrollada por el párroco que ocupó la iglesia principal del municipio, el templo dedicado a San Pedro Apóstol, los pedranos establecen una clara distinción entre el tradicionalismo religioso, el catolicismo y el protestantismo. A diferencia de Oxchuc, la labor católica fue bastante más intensa entre los pedranos desde antes de la incursión protestante. Eso y, digamos, una conflictividad que no amenazaba las estructuras de control social, a pesar de la labor realizada por distintas organizaciones populares de izquierda, operó como bastión para contener su avance (ver Page op. cit.)

Aun, y a pesar de esto, la cosmovisión de los tsotsiles pedranos, quienes en la actualidad dada la conflictividad religiosa se autodenominan tradicionalistas, es muy semejante a la de los chamulas en cuanto a su estructura y sistematización, aspecto sobre el que no me extenderé en este trabajo pero que denota una importante labor de resistencia desplegada durante siglos para no perder el control cultural.

Por otro lado, a diferencia de Chamula, en Chenalhó los tsotsiles profesores bilingües originarios del municipio fueron los que se hicieron con el poder civil. Como primer presidente municipal se nombró a Manuel Arias Sojob:

... uno de los pocos tzotziles bilingües y alfabetizados, quien tenía la particularidad de haber participado en las fuerzas carrancistas durante la Revolución, Arias Sojob, al frente de sus allegados, tramitó y logró fundar, no sin serios problemas con los mestizos, la primera escuela primaria para su pueblo. Este hecho resalta, pues fue precisamente el sector magisterial pedrano el que toma el poder, esgrimiendo la educación como condición para avanzar en el escalafón político de Chenalhó; creándose, con ello, el surgimiento de grupos de [elite] entre los tzotziles pedranos y, en consecuencia, una diferencia de status con la mayoría de la población analfabeta (Page 2005: 51). 
En el posicionamiento de los maestros fue fundamental su afiliación al Partido Nacional Revolucionario, PNR, que posteriormente derivaría en el Partido Revolucionario Institucional, PRI, de quienes se valdría para dar cauce a las organizaciones de masa subordinadas al Estado (Rus 1995b: 261).

\section{OXCHUC}

Oxchuc, habitado por tseltales, es uno de los municipios más pobres y marginados de Los Altos de Chiapas. Se caracteriza por una orografía pedregosa y carente de agua en la mayor parte de su territorio. Los documentos históricos sitúan inicialmente a Oxchuc como dependiente de otros centros poblacionales:

En el siglo XVI, las autoridades coloniales dan a Oxchuc el carácter oficial de poblado, adscribiéndolo al departamento y partido de Chilón (Siverts 1969: 51). Según refiere Viqueira (1987: 388), en el siglo XVII Oxchuc se incluía a lo que dio en llamarse Montañas Zendales, por lo cual no se caracterizaba por su unidad interna ya que estaba fragmentado en varias guardianías. La administración era detentada por grupos religiosos, así Oxchuc, Tenejapa y Huixtán, formaban parte del convento de Ciudad Real, que estaba a cargo de la orden de los predicadores (Page 2010: 13).

La anterior cita deja ver la poca importancia que para la sociedad colonial tenía el municipio, desinterés que no solo se concretó en el hecho de quedar relegado administrativamente, sino también en relación con la evangelización católica (Villa Rojas 1990, Viqueira 1987).

Hacia 1930 Oxchuc fue adscrito al municipio de Ocosingo, y en 1936 alcanza el estatus de municipio libre (Siverts 1969: 51).

La organización social previa a 1940 estaba fundada en una jerarquía de orden religioso. Distinguía a la población en dos Kalpuletik: el Mukul Kalpul o de Santo Tomás, patrón del municipio; y el Chin Kalpul, de la Santísima Trinidad, cada cual con su propia jerarquía encabezada por el K’atinab (Villa Rojas 1990: 28). 
Respecto de la forma del Kalpuletik como forma de gobierno, Villa Rojas (1990), Siverts (1969) y Harman (1990), señalan que inició su deterioro debido a que estaba fundamentada en el ak'chamel o tz'ilajwanej, cuyo significado aproximado es «mal echado», con la consecuente violencia social que ello implicaba además de que la población vivía prácticamente gobernada por el miedo. Según señala Favre (1973: 249250), a partir de 1900 ningún K’atinab murió de causas naturales, y desde 1920 ningún anciano se arriesgó a aceptar el cargo.

Otro antecedente de importancia es que antes de la década de 1930 no había presencia ladina $^{4}$ en el municipio. Estos inmigraron de otros municipios del estado para asentarse en la cabecera municipal; ya en la década de 1940 prácticamente se habían adueñado del Centro ceremonial.

Los ladinos fincaron su economía en la exacción de la población tseltal, mediante el despojo, el endeudamiento, principalmente por compra de pox —aguardiente- y el reclutamiento — «enganchamiento»— de hombres como mano de obra para las fincas de tierra caliente.

Hacia la década de 1960, como resultado del trabajo realizado por DASCPI, así como el llevado a cabo por la Iglesia presbiteriana, la población ladina en su mayoría fue expulsada de Oxchuc.

Por otro lado, la política de sustitución de autoridades emprendida por DASCPI en la década de 1930 tuvo que enfrentar el poder no de una jerarquía religiosa bien cimentada, sino de los ladinos. Como en Chenalhó, donde el gremio magisterial tseltal afiliado a PRN fue el que se hizo del poder, cuyo devenir tuvo sus particularidades específicas, dada una conflictividad social diferente a la de otros municipios (ver Page 2010). 
En el caso de Chamula, a partir de los datos vertidos uno esperaría encontrar una cosmovisión bien cimentada, con múltiples elementos prehispánicos, perfectamente estructurada, con la religiosidad rigiendo la moralidad y la vida. Sin embargo, a mi manera de ver, este pueblo desde su conformación careció del conocimiento necesario para preservar suficientes elementos prehispánicos; por otro lado, la falta de interés de la Iglesia católica en los recursos del municipio tuvo como resultado el no llevarse a cabo, como se hizo en otros ámbitos, la evangelización de la población, por lo que también les faltó este recurso para que se diera una estructura sociorreligiosa a la par de los pueblos vecinos. Lo cual claramente trasluce en las prácticas médicas.

A diferencia de lo que hemos podido observar en Chamula y Chenalhó, al estudiar desde una perspectiva etnomédica los procesos de salud-enfermedad-atención en los que el estar sano o enfermo depende en gran medida de la dedicación con que se atienda a la divinidad, en la sanción que estas hacen del comportamiento humano, tanto en grupo como individualmente, en Oxchuc el control social fue ejercido, sí, desde lo sobrenatural, pero desde un plano que podríamos de alguna manera denominar no divino, pues no involucra a los dioses, toda vez que dicha función fue ejercida por los ancianos «Cabeza de linaje» y por todo aquel que se considerara, al igual que los primeros, poseedor de un $l a b,{ }^{5}$ entidad a la que podríamos rápidamente caracterizar con Lupo (1999: 17) como:

\footnotetext{
...la creencia de que determinados individuos — los cuales a menudo ocupan puestos sociales importantes- están investidos de poderes espirituales particulares, que les permiten transformarse asumiendo a su gusto semblanzas animales —o también, en raras ocasiones de fenómenos naturales como rayos, viento, nubes, bolas de fuego, etc.- y realizar bajo tales «disfraces» acciones prodigiosas.
}

Dinámica social indudablemente marcada por el miedo y los consecuentes convencionalismos, en el sentido de que era necesario constantemente halagar a dichos personajes y sobre todo cuidarse de ofenderles, ya que la salud, la enfermedad y casi siempre la muerte, se consideraba podía depender de su voluntad. 
En consecuencia, la atención de las enfermedades y otros infortunios, según señaló Villa Rojas (1990: 341), se daba sobre la base de la reunión de varios individuos de los dotados con la capacidad de ver, con lab, quienes en círculo pulsaban al enfermo con objeto de desenmascarar al «brujo» que estaba ocasionando el daño. Viéndose entonces condicionada toda relación y transacción por el matiz que imponía la presencia constante y amenazante del ak'chamel.

\section{RELIGIOSIDAD}

Como se señala arriba, uno de los factores centrales en la trasformación que se ha suscitado en los sistemas etnomédicos puede atribuirse a cambios significativos en la religiosidad. Aspecto al que me he referido en otros trabajos, pero que traigo a colación para estar en posibilidad de hacer una comparación desde lo que considero son los determinantes más importantes.

A partir de los someros perfiles esbozados, resultado de las particulares historias de cada pueblo, podemos ver la conformación de tres perfiles religiosos distintos. Chamula, como ya se señaló, con una estructura religiosa sólida, unívoca en el sentido tradicionalista, bien estructurada conceptualmente, dominante, que rechazó violentamente la intromisión de cualquier otro sistema religioso. En Chenalhó, municipio que da cabida a tradicionalistas, católicos y protestantes, se sitúa lo religioso subsumido por el poder civil, con una conflictividad poco significativa entre las partes. No obstante en Oxchuc, carcomido por el miedo a expensas de un sistema de control social controlado por el $a k^{\prime}$ chamel o mal echado, todo lo acaecido coadyuva a perfilar cambios mucho más rápidos que en los otros municipios.

Debido a lo anterior empezaré por referirme con mayor extensión a Oxchuc, dado que la acción proselitista inició en este municipio para después extenderse por todo Los Altos de Chiapas.

El presbiterianismo tomó fuerza en la comunidad de Corralito, del municipio de Oxchuc, en el año 1949, cuando la estrategia proselitista finalmente rindió el fruto de la 
afiliación. A partir de lo cual en el plazo de cinco años de trabajo se logró que cerca de la mitad de la población se convirtiera. Más adelante, en respuesta a la acción de la nueva Iglesia católica, realizada a partir de la década de 1960, aumenta significativamente el porcentaje de población conversa.

En la actualidad la población que aún se considera tradicionalista es mínima, predomina la población con filiación protestante, seguida de cerca del catolicismo y, como ha observado García Sosa (2005: 102), se puede ver una clara tendencia a la participación conjunta en el devenir social y religioso, así como todavía gran temor generalizado hacia la acción de los labetik y el ak'chamel.

En Chamula, la institución religiosa tradicionalista se ubica por encima del poder civil y es determinante en las formas de control y solución de la problemática social. Municipio en el que en la actualidad el tradicionalismo es practicado por más de $80 \%$ de la población bajo la consideración de que, de pocos años a la fecha, algunas comunidades del municipio han optado por el protestantismo, defendiendo su opción e impidiendo su expulsión.

Por lo que toca al protestantismo en Chamula, hasta 1968 solo veinte familias se habían convertido (Robledo 1987: 81-87). Y en la década de 1970, debido a que un amplio sector de Chamula se opuso a los tuxumetik, se dieron las condiciones para el avance de distintos grupos religiosos. En cuanto al protestantismo, el índice de conversiones se incrementó significativamente, ya que en 1972 pasó de veinte a ochenta familias, sumando en 1976 más de ochocientas, todas las cuales fueron violentamente expulsadas del municipio, lo que no se tradujo en impedimento para el crecimiento exponencial de los conversos, que no solo lo hicieron hacia el presbiterianismo, sino también hacia el adventismo y pentecostalismo (ibídem), y actualmente hacia el islamismo.

En Chenalhó, a partir de la década de 1930 fueron los profesores de origen tsotsil los que se hicieron con el poder, además nos encontramos con el antecedente de una acción católica estrechamente vinculada con la población tsotsil, factor que si bien no impidió 
la acción religiosa protestante que en el municipio inició hacia 1958 constituyó un impedimento para su avance. Desde la perspectiva religiosa, en la actualidad los pedranos se distinguen a sí mismos como tradicionalistas, católicos, y protestantes. Sobre el particular, a partir de una encuesta realizada en 1985, Pérez Enríquez (1994: 165) registró la siguiente distribución religiosa: tradicionalistas 51\%; católicos eclesiásticos 15\%; presbiterianos 15\%; adventistas $4 \%, y$ sin religión $4 \%$. Diferenciándose claramente tradicionalistas de católicos, por efecto del deslindamiento que en su momento hizo la Iglesia católica.

En Chenalhó, la conflictividad sociorreligiosa ha sido mínima, y lo que más bien se ha suscitado son procesos de búsqueda de consenso, tendientes a la convivencia armónica entre los adeptos de las distintas Iglesias y asociaciones, predominando todavía el tradicionalismo.

\section{PROCESO SALUD-ENFERMEDAD-ATENCIÓN Y PERTINENCIA CULTURAL}

Hasta aquí he delineado tres perfiles de los que enseguida se presentan las correspondencias que cada cual tiene con los sistemas etnomédicos a que dan lugar, así como las diferencias entre éstos (ver Cuadro 1).

En el caso de Chamula encontramos un sistema etnomédico integrado al ámbito religioso, por lo que además de sus características particulares hasta mediados de la década del año 2000 constituía una instancia determinante en el ejercicio del control social del municipio, en el sentido de que aquellos enfermos que no asistían a éste como primera opción de atención se les acusaba de ser protestantes o católicos.

Asimismo, el carácter religioso de la etnomedicina, lo que también aplica en Chenalhó, se esclarece a partir del hecho de que la salud, la enfermedad y la muerte, en buena medida dependen del adecuado desempeño moral de las personas tanto en sus vidas particulares como en sus actos sociales. Y en la medida en que en cualquiera de los dos ámbitos se producen trasgresiones, se generan mecanismos que acarrean enfermedad e infortunio. 
En los casos de Chenalhó y Oxchuc, los correspondientes sistemas etnomédicos están lejos de regir la vida sociopolítica, limitando su acción a los ámbitos doméstico y ritual, encaminada a las peticiones colectivas con motivo de las siembras.

En cuanto a lo propiamente etnomédico, hemos topado con una inusitada similitud entre los sistemas etnomédicos presentes en Chamula y Chenalhó, lo cual atribuimos al hecho de que existe una constante interacción social y económica entre ambos municipios debido fundamentalmente a que son aledaños, lo que implica una interacción constante entre sus habitantes, destacándose el hecho de que los jpoxtavanejetik - los que ayudan a sanar- deambulan entre uno y otro municipio, atendiendo las solicitudes de los familiares de los enfermos, además de que los habitantes de ambos municipios coexisten en los mercados; es decir, se suscitan un sinnúmero de eventos en los que se comparten formas de ver y de vivir el mundo, lo que coadyuva a la unificación de las representaciones sociales.

Por otro lado, el sistema etnomédico de Oxchuc en tanto su precedente, esto es el llevado a cabo hasta antes de la impronta protestante, como el actual difieren con los de Chamula y Chenalhó y entre sí.

En lo que toca a las deidades, se sabe que en Chamula y Chenalhó se consideraba que gravitaban a voluntad entre el bien y el mal, actuando de un lado a otro según sus conveniencias, o sea de la calidad de la ofrenda dada a cambio de aceptar la petición, de favorecer a sus hijos predilectos, etcétera. Esto a su vez daba lugar a que los correspondientes agentes médicos estuvieran en capacidad de ayudar o dañar al prójimo.

Mientras que en Oxchuc todo gravitaba en torno al control que se establecía entre los pik'abaletik ya que, como antes se señaló, en las reuniones que se organizaban para atender a los enfermos siempre se procuraba que la persona de quien se sospechaba había causado el daño estuviera presente, de tal manera que al saltar el pulso al 
nombrársele, implicando ello su injerencia en el asunto, se viera obligado a retirar el daño y que la persona pudiera sanar (Villa Rojas 1990: 341).

Posteriormente, como resultado del discurso satanizador y descalificador vertido por los diferentes grupos cristianos en Los Altos de Chiapas, se produce, para los tres municipios que nos ocupan, la ruptura de un elemento de la larga duración de la cosmovisión (Braudel 1999: 94), dando como resultado la ubicación de las distintas deidades y sus huestes del lado del bien o del mal para, en consecuencia, en adelante ser poxtavanej implicaba ser hijo de Dios, mientras que ser j-ak'chamel o j-tz'ilajwanej — echador de enfermedad o de muerte — lo es ser del Pukuj —Diablo. 
Cuadro 1. Pertinencia sociocultural en el proceso salud-enfermedad-atención, los casos de Chamula, Chenalhó y Oxchuc, Chiapas

\begin{tabular}{|c|c|c|c|c|c|c|}
\hline & \multicolumn{2}{|c|}{ Chamula } & \multicolumn{2}{|c|}{ Chenalhó } & \multicolumn{2}{|c|}{ Oxchuc } \\
\hline $\begin{array}{l}\text { Deidades } \\
\text { Ejercicio del } \\
\text { Control social }\end{array}$ & $\begin{array}{l}\text { Anteriormente } \\
\text { Bien/Mal } \\
\text { Religión/Deida } \\
\text { des }\end{array}$ & $\begin{array}{l}\text { Actualidad } \\
\text { Bien o Mal } \\
\text { Religión } \\
\text { /deidades }\end{array}$ & $\begin{array}{l}\text { Anteriormente } \\
\text { Bien/Mal } \\
\text { Poder civil }\end{array}$ & $\begin{array}{l}\text { Actualidad } \\
\text { Bien o Mal } \\
\text { Poder civil }\end{array}$ & $\begin{array}{l}\text { Anteriormente } \\
\text { Mal } \\
\text { Ancianos }\end{array}$ & $\begin{array}{l}\text { Actualidad } \\
\text { Bien o mal } \\
\text { Poder civil }\end{array}$ \\
\hline $\begin{array}{l}\text { Principales } o \\
\text { cabeza de linaje }\end{array}$ & $\begin{array}{l}\text { Función } \\
\text { protectora/daño }\end{array}$ & $\begin{array}{l}\text { Función } \\
\text { protectora }\end{array}$ & $\begin{array}{l}\text { Función } \\
\text { protectora/dañ } \\
\text { o }\end{array}$ & $\begin{array}{l}\text { Función } \\
\text { protectora }\end{array}$ & Bien/mal & Bien/mal \\
\hline \multirow[t]{2}{*}{ Poxtavanejetik } & j-ilol bien/mal & Bien & j-ilol bien/mal & Bien & Bien/mal & $\begin{array}{l}\text { Pik'abal- } \\
\text { hierbatero }\end{array}$ \\
\hline & $\begin{array}{l}\text { Hijo Dios y del } \\
\text { Diablo }\end{array}$ & Hijo de Dios & $\begin{array}{l}\text { Hijo Dios y } \\
\text { del Diablo }\end{array}$ & Hijo de Dios & $\begin{array}{l}\text { Hijo Dios y } \\
\text { del Diablo }\end{array}$ & Hijo de Dios \\
\hline \multirow[t]{2}{*}{ j-ak'chameletik } & $\begin{array}{l}\text { j-ilol bien/mal } \\
\text { j-ak'chamel } \\
\text { Mal }\end{array}$ & Mal & $\begin{array}{l}j \text {-ilol bien/mal } \\
j \text {-ak'chamel } \\
\text { Mal }\end{array}$ & Mal & Mal & Mal \\
\hline & $\begin{array}{l}\text { Hijo de Diablo } \\
\text { y de Dios }\end{array}$ & Hijo de Diablo & $\begin{array}{l}\text { Hijo de } \\
\text { Diablo y de } \\
\text { Dios }\end{array}$ & $\begin{array}{l}\text { Hijo de } \\
\text { Diablo }\end{array}$ & $\begin{array}{l}\text { Hijo de } \\
\text { Diablo y de } \\
\text { Dios }\end{array}$ & $\begin{array}{l}\text { Hijo de } \\
\text { Diablo }\end{array}$ \\
\hline Altar & Indispensable & Indispensable & Indispensable & Indispensable & $\begin{array}{l}\text { Presente sin } \\
\text { ser el centro } \\
\text { del ritual }\end{array}$ & Prescindible \\
\hline $\begin{array}{l}\text { Ofrendas } \\
\text { (materia } \\
\text { sagrada) }\end{array}$ & Indispensable & Indispensable & Indispensable & Indispensable & Indispensable & Prescindible \\
\hline $\begin{array}{l}\text { Plantas } \\
\text { olorosas }\end{array}$ & Indispensable & Indispensable & Indispensable & Indispensable & Indispensable & Prescindible \\
\hline Velas/copal & Indispensable & Indispensable & Indispensable & Indispensable & Indispensable & Prescindible \\
\hline $\begin{array}{l}\text { Sacrificio de } \\
\text { animales }\end{array}$ & Indispensable & $\begin{array}{l}\text { Se observa su } \\
\text { gradual } \\
\text { erradicación }\end{array}$ & Indispensable & $\begin{array}{l}\text { Se observa su } \\
\text { gradual } \\
\text { erradicación }\end{array}$ & Indispensable & Prohibido \\
\hline $\begin{array}{l}\text { Bebidas } \\
\text { embriagantes }\end{array}$ & Indispensable & Prescindible & Indispensable & Prescindible & Indispensable & Prohibido \\
\hline Refresco & No presente & Indispensable & No presente & Indispensable & No presente & $\begin{array}{l}\text { Presente no } \\
\text { indispensable }\end{array}$ \\
\hline Materia médica & $\begin{array}{l}\text { Presente no } \\
\text { indispensable }\end{array}$ & $\begin{array}{l}\text { Presente no } \\
\text { indispensable }\end{array}$ & $\begin{array}{l}\text { Presente no } \\
\text { indispensable }\end{array}$ & $\begin{array}{l}\text { Presente no } \\
\text { indispensable }\end{array}$ & $\begin{array}{l}\text { Presente no } \\
\text { indispensable }\end{array}$ & Indispensable \\
\hline $\begin{array}{l}\text { Herbolaria } \\
\text { medicinal }\end{array}$ & $\begin{array}{l}\text { Presente no } \\
\text { indispensable }\end{array}$ & $\begin{array}{l}\text { Presente no } \\
\text { indispensable }\end{array}$ & $\begin{array}{l}\text { Presente no } \\
\text { indispensable }\end{array}$ & $\begin{array}{l}\text { Presente no } \\
\text { indispensable }\end{array}$ & $\begin{array}{l}\text { Presente no } \\
\text { indispensable }\end{array}$ & Indispensable \\
\hline $\begin{array}{l}\text { Hidroterapia } \\
\text { (Puz) }\end{array}$ & Parto & Parto & Parto & Parto & $\begin{array}{l}\text { Indispensable } \\
\text { Muy utilizado }\end{array}$ & $\begin{array}{l}\text { Indispensable } \\
\text { Muy utilizado }\end{array}$ \\
\hline Huevo & Ausente & $\begin{array}{l}\text { Presente no } \\
\text { indispensable }\end{array}$ & Ausente & $\begin{array}{l}\text { Presente no } \\
\text { indispensable }\end{array}$ & Ausente & Ausente \\
\hline $\begin{array}{l}\text { Plantas } \\
\text { carminativas } \\
\text { (limpias) } \\
\end{array}$ & Ausente & $\begin{array}{l}\text { Presente no } \\
\text { indispensable }\end{array}$ & Ausente & $\begin{array}{l}\text { Presente no } \\
\text { indispensable }\end{array}$ & Ausente & Ausente \\
\hline $\begin{array}{l}\text { Medicina de } \\
\text { Farmacia }\end{array}$ & Ausente & $\begin{array}{l}\text { Presente no } \\
\text { indispensable }\end{array}$ & Ausente & $\begin{array}{l}\text { Presente no } \\
\text { indispensable }\end{array}$ & Ausente & $\begin{array}{l}\text { Presente no } \\
\text { indispensable }\end{array}$ \\
\hline
\end{tabular}

Fuente: elaboración propia 
En lo que toca a los agentes etnomédicos, en los sistemas religiosos mejor estructurados de Chenalhó y Chamula los j-iloletik antes y ahora desempeñan una labor predominantemente sacerdotal, en tanto que en Oxchuc anteriormente todo giraba en torno al daño que entre unos y otros se enviaban, mientras que en la actualidad la mayoría de los j-poxtawanejetik aprenden a diagnosticar bajo rudimentos de la clínica alopática incorporados al conocimiento tradicional, y basan sus tratamientos en la herbolaria medicinal, la hidroterapia —esencialmente el baño de vapor (puz) - y eventualmente el rezo.

Ciertamente, en Oxchuc hay quienes hoy aún se dedican a echar mal, y quienes ayudan a sanar las enfermedades derivadas de ello, pero cada día son menos y más difíciles de localizar. Sin embargo éstos, a diferencia de los procedimientos de que se valen los tsotsiles, no se encomiendan ni interceden entre las deidades y los enfermos, sino que entablan batallas verbales con los labetik «dañeros».

Respecto de la obtención del cargo o mandato, para los tsotsiles de antes y ahora la revelación onírica ha sido un factor fundamental, ya que por su intermedio no solo se adquiere el conocimiento y el poder sino que a la vez valida, ante las deidades y los hombres, la tarea a desempeñar. En tanto que en Oxchuc el poder era y es inherente a la persona proviniendo de la posesión de lab. Este aspecto linda precisamente con la ruptura del elemento de la larga duración a que se hace alusión más arriba, en el sentido de que la acción religiosa cristiana incidió en el tradicionalismo a tal grado que la satanización de sus deidades y sus prácticas indefinidas provocaron la separación de las deidades en dos grupos, las deidades del bien y las del mal, lo que a su vez incidió en la trasformación de la estructura del sistema etnomédico en el sentido de que los practicantes se escindieron, entre los tsotsiles en j-ilol/j-ak'chamel, y entre los oxchuqueros en pik'abal/tz'ilajwanej, ya que en el pasado, como señala Holland, los $j$ iloletik y los pik'abaletik estaban en posición de ayudar a sanar o echar mal:

Los tzotziles creen que los poderes ocultos y misteriosos de la hechicería y de la curación se adquieren con frecuencia por medios similares. En ambos casos el ser sobrenatural revela sus conocimientos secretos y dota de sus poderes ocultos a un individuo en sus sueños. Si un 
individuo será curandero, tiene un sueño en el que los dioses ancestrales de su montaña sagrada sacan a su animal compañero de su lugar, lo llevan a sus habitaciones especiales donde le revelan los rituales curativos y los tratamientos para varias enfermedades. El futuro curandero aprende a tomar el pulso, a construir el altar para la curación, cuáles han de ser las velas adecuadas, el incienso, las hierbas empleadas para cada enfermedad, cómo pasar la gallina, y cómo dirigirse a los dioses en la oración. Se le da a cada curandero una fórmula curativa diferente. Cuando los dioses benévolos terminan de instruirlo, se le ordena pasar al cuarto siguiente, atravesándolo sin detenerse, y regresar directamente a su lugar correspondiente. En este cuarto hay varios dioses ancestros malignos sentados alrededor de una mesa, sobre la que están unas bebidas en botellas de varios colores; al pasar lo invitan a sentarse a la mesa y a beber un trago. Si sucumbe a la tentación, en lugar de pasar por el cuarto sin detenerse como se le había ordenado aprende entonces a enviar la enfermedad tanto como a alejarla (Holland 1963: 134).

De esta manera, en la actualidad, en los tres municipios, como resultado de la reubicación de las deidades, quienes detentan algún mandato en el proceso de atender la enfermedad o causarla se adscriben unívocamente a un extremo de la dicotomía bien/mal: o se es hijo de Dios o del Diablo.

Otro aspecto a considerar es que entre los tsotsiles los $j$-iloletik prevalecen como figura central en la etnomedicina, en tanto que en Oxchuc el tz'ilajwanej prácticamente ha desaparecido a consecuencia del exterminio a que estos sujetos fueron sometidos entre las décadas de 1920 a 1950, (Page 2010: 174), por lo mismo, en las entrevistas realizadas en Oxchuc, en la mayoría de los testimonios se dice que actualmente ya no se les ve, y escasamente se escucha de ellos:

Un día mi papá nos contó que vio que estaban matando a muchos viejitos, pero a él no le pasaba nada ya que él no le había hecho nada a la gente. Eso quiere decir que no tenía delito (Page 2010: 104).

Asimismo, entre los oxchuqueros actuales, además de que se considera que la mayoría de los j-poxtavanejetik se encuentra del lado del bien, el aprendizaje no se da por la vía onírica. Generalmente, tal como reza el siguiente testimonio, el oficio se adquiere por 
aprendizaje con los progenitores, escuchando y practicando se logra experiencia clínica y el conocimiento de la herbolaria y otros recursos:

\footnotetext{
...Bueno, yo aprendí de curar hasta que me casé con mi mujer, creo que tenía como 25 años cuando empecé y ahora ya tengo 64 años, y ahora como mis padres murieron y como me enseñaron antes de que se murieran, o sea si hay calentura, fuego en la boca de los niños y otras más que curaba mi difunto papá, entonces allí lo vi todo, y cuando se murieron yo mismo empecé a hacer la prueba de curar y los enfermos sanaron, allí seguí curando a los enfermos, y así poco a poco fui aprendiendo más, ya que estamos en una organización (Page 2010: 178).
}

Respecto del altar, por efecto del discurso protestante, en la práctica curativa actual de los oxchuqueros, que no en la de protección, este deja de ser un factor crucial toda vez que ya no se elevan plegarias ni se hacen ofrendas buscando la restitución de la salud, sino que se concibe que el remedio que se ingiera o el baño que se reciba, por los principios activos que contienen, por su efecto eliminará la enfermedad. Se le agradece a Dios, pero no se espera que restituya la salud. Por lo mismo, lo que he denominado materia sagrada — plantas aromáticas, fuego, olores, etc. — son factor prescindible.

Sin embargo, entre los tsotsiles tradicionalistas, con importantes cambios, sigue siendo indispensable. Son varios los elementos que desaparecen del altar y del ritual para ayudar a sanar: cada vez se observa menos la presencia de velas negras y rojas, colores adscritos al mal, el pox no es más nutrimento de la deidad celestial, por lo que es retirado del altar para ser colocado a un lado del/la $j$-ilol y solo es ingerido para ser asperjado sobre el altar con objeto de confundir al maligno; asimismo, el sacrificio de gallos y gallinas se observa cada vez menos, algunos de los que lo utilizan como recurso terapéutico solo limpian al enfermo pero no matan a la gallina, sin embargo en las ceremonias curativas que se llevan a cabo en el templo de Chamula aún se observa con relativa frecuencia el sacrificio de aves.

En lo que respecta a la materia médica, entre los tsotsiles, no es indispensable o constituye un factor secundario cuando se trata de enfermedades a las que se considera de causalidad sobrenatural, toda vez que basta con el rezo para ayudar a la mayoría de 
estos enfermos a recuperar la salud. Por otro lado entre los oxchuqueros, si bien se considera que este tipo de enfermedades se presenta cada vez menos, como ya no existen «dañeros», cuando lo hace los enfermos buscan a personas que se sabe pueden ayudar en este tipo de situaciones, ya en la cabecera municipal del municipio o ya en otros municipios como Ocosingo, Tenejapa o Cancuc.

\section{CONCLUSIÓN}

La perspectiva histórica respecto del devenir de las etnomedicinas en Chamula, Chenalhó y Oxchuc, nos indica que diversos devenires apuntan a diferentes consecuencias. La manera en que se suscitaron los acontecimientos socioeconómicos, religiosos y culturales, enmarcados en relaciones diferentes, aunque siempre en desventaja, entre las poblaciones mayas que nos ocupan y los grupos dominantes del estado de Chiapas, así como con instituciones de la Federación, coadyuvaron a la conformación de prácticas etnomédicas diferenciadas entre Chamula, Chenalhó y Oxchuc. En el primer caso, el componente central antes y ahora ha sido la intermediación sacerdotal del $j$-ilol entre los tsotsiles que nos ocupan y las deidades en el proceso de recuperar la salud o subsanar algún infortunio.

En tanto que en Oxchuc, además de que nunca estuvo presente en las prácticas relacionadas con los eventos de salud-enfermedad-muerte el aspecto religioso a la manera de Chamula y Chenalhó, toda vez que se circunscribían al ámbito del tz'ilajwanej - mal echado-, el volumen de conversión del tradicionalismo principalmente hacia el protestantismo, y en forma secundaria hacia el catolicismo, debido, por un lado, a la preponderante satanización, descalificación y consecuente persecución a que en diferentes momentos fueron sujetos los pik'abaletik y, por otro, a los contenidos ideológicos que favorecen el uso y consumo de la biomedicina por los protestantes; va generando que gradualmente los conceptos y la práctica médica se vayan asemejando a la práctica realizada en el ámbito alopático.

Como hemos visto, uno de los factores de mayor importancia en la trasformación de los sistemas etnomédicos, en los tres casos, es el religioso. De hecho, en diferentes foros he 
sostenido que la acción indigenista no logró erradicar las prácticas etnomédicas, como se lo proponía, así como las acciones del sector salud, debido a que han pretendido incidir únicamente en el ámbito de la práctica, sin hacerlo en el plano ideológico.

En contraparte, es la acción religiosa la que se enfoca en el sentido ideológico y logra en el corto plazo, por el lado de la etnomedicina entre chamulas y pedranos, si no erradicarla sí logra romper un elemento fundamental de los de larga duración, que genera la separación de la dicotomía de las deidades en polos separados, con la consecuente modificación de las prácticas, y sí la erradicación de aquellas más satanizadas por los grupos religiosos, prevaleciendo la religiosidad tradicional como determinante central del proceso de salud-enfermedad-atención.

En Oxchuc, donde, entre otras cosas la conversión religiosa obedeció de manera importante a la posibilidad de quedar a salvo de los efectos del tz'ilajwanej — mal echado-, la práctica médica y su corpus cambiaron de un polo a otro, no solo para cortar espacios de acción y de manifestación al ak'chamel — dejar de jugar el juego, según Bourdieu 2005-, como por la coherencia requerida con la nueva ideología, en el sentido de no entrar en contradicción con los elementos del tradicionalismo y el tz'ilajwanej que esta descalifica y sataniza; destacando, dentro de las posibilidades del grupo, elementos que la ideología por la que se ha optado propone como positivos, es decir, los provenientes de la medicina alopática, o al menos que no se pronuncia negativamente sobre aquellos que permanecen como remanentes insustituibles, como la herbolaria medicinal, derivado de la pobreza de la gente, y por ello su imposibilidad de acceder a la farmacia frecuentemente, por no decir que nunca. 


\section{REFERENCIAS BIBLIOGRÁFICAS}

Bautista Martínez, Roberto Alejandro, 2002, «Espacios disputados y poder local en Oxchuc, Chiapas». Tesis de licenciatura. Facultad de Ciencias Sociales, Universidad Autónoma de Chiapas, San Cristóbal de Las Casas, Chiapas.

Bourdieu, Pierre, 2005, «Alta costura y alta cultura». En Teoría y análisis de la cultura. 2 volúmenes, Conaculta, Colección Intersecciones, México, tomado de Sociología y cultura, Editorial Grijalbo, México, 1990, pp. 215-224. Conferencia presentada en Noroit, Arras, en noviembre de 1974, y publicada en Noroit, n. 192, noviembre de 1974, pp. 1-2 y 7-17; y ns. 193-194, diciembre de 1974, pp. 2-11.

Braudel, Fernand, 1999, La historia y las ciencias sociales. Alianza Editorial, España.

Fabrega Jr. ; Horacio and Daniel B.Silver, 1973, Illness and shamanistic curing in Zinacantan. Stanford University Press, USA.

Favre, Henri, 1973, Cambio y continuidad entre los mayas de México. Editorial Siglo XXI, México.

García de León, Antonio, 1985, Resistencia y Utopía. Ediciones Era, México.

García Sosa, Juan Carlos 2005, «Manejo terapéutico de enfermos oculares: el tracoma en una localidad tseltal del Oxchuc, Chiapas». Tesis de maestría. Centro de Investigaciones y Estudios Superiores en Antropología Social-Sureste, San Cristóbal de Las Casas, Chiapas.

Garza Caligaris, Anna María, 1999, «El género entre normas en disputa: Pluralidad legal y género en San Pedro Chenalhó». Tesis de maestría. Facultad de Ciencias Sociales-Universidad Autónoma de Chiapas, San Cristóbal de Las Casas, Chiapas. 
Gossen H., Gary, 1980, Los chamulas en el mundo del Sol. Tiempo y espacio en una tradición oral Maya. Consejo Nacional para la Cultura y las Artes/Instituto Nacional Indigenista, México.

Guiteras Holmes, Calixta, 1965, Los peligros del alma, Fondo de Cultura Económica, México.

1992, Cancuc. Etnografía de un pueblo tzeltal de Los altos de Chiapas 1944, Consejo Estatal de Fomento a la Investigación y Difusión de la Cultura, Serie Nuestros Pueblos, Chiapas, México.

Harman, Robert C., 1990 [1974], Cambios médicos y sociales de una comunidad mayatzeltal. Instituto Nacional Indigenista/Consejo Nacional para la Cultura y las Artes, México.

Hermitte, M. Esther, 1970, Poder sobrenatural y control social en un pueblo maya Contemporáneo. Consejo Estatal de Fomento a la Investigación y la Difusión de la Cultura, Colección Cuadernos Municipales, Chiapas, México.

Holland R., William, 1963, Medicina maya en los altos de Chiapas: Un estudio del cambio socio-cultural. Instituto Nacional Indigenista, México.

Köhler, Urlich, 1995, Chonbilal Ch'ulelal-Alma Vendida. Elementos fundamentales de la cosmología y religión mesoamericanas en una canto maya-tzotzil. Instituto de Investigaciones Antropológicas, Universidad Nacional Autónoma de México, México.

Lupo, Alessandro, 1999, «Nahualismo y tonalismo». Arqueología Mexicana, v. VI, n. 35, pp. 16-23, enero-febrero, Conaculta, México. 
Medina Hernández, Andrés, 1991, Tenejapa: Familia y tradición en un pueblo tseltal. Consejo Estatal de Fomento a la Investigación y Difusión de la Cultura, Serie Nuestros Pueblos n. 6, Chiapas.

2000, En las cuatro Esquinas/En el Centro. Etnografía de la Cosmovisión Mesoamericana. Instituto de Investigaciones Antropológicas, Universidad Nacional Autónoma de México, México.

Menéndez, Eduardo L., 2002, La parte negada de la cultura. Relativismo, diferencias y racismo. Ediciones Bellaterra, Serie General Universitaria n. 16, España.

Moguel Viveros, Reyna y Manuel R. Parra Vázquez, 1998, «Los ladinos rurales de Huixtán y Oxchuc: un caso de involución social». En Espacios disputados: transformaciones rurales en Chiapas, coordinado por María Eugenia Reyes Ramos, Reyna Moguel Viveros y Gemma Van del Haar. Universidad Autónoma MetropolitanaXochimilco/El Colegio de la Frontera Sur/WAU/CEDLA, México.

Page Pliego, Jaime, 2005, El mandato de los dioses: Medicina entre los tzotziles de Chamula y Chenalhó, Chiapas. Programa de Investigaciones Multidisciplinarias sobre Mesoamérica y el Sureste, Instituto de Investigaciones Antropológicas, Universidad Nacional Autónoma de México, Serie Científica n. 11, México.

2007, «Vivir en el miedo. La noción de lab en Oxchuc, Chiapas». Revista Pueblos y fronteras digital, n. 4, http://www.pueblosyfronteras.unam.mx, Programa de Investigaciones Multidisciplinarias sobre Mesoamérica y el Sureste, Instituto de Investigaciones Antropológicas, Universidad Nacional Autónoma de México, México.

2010, Yombil «Puesta su flor en el altar». Una mirada a la etnomedicina en Oxchuc, Chiapas, a partir de los j-poxtawanejetik organizados. Programa de Investigaciones Multidisciplinarias sobre Mesoamérica y el Sureste, Instituto de Investigaciones Antropológicas, Universidad Nacional Autónoma de México, México. 
Pérez Enríquez, María Isabel, 1994, Expulsiones indígenas. Religión y migración en tres municipios de los Altos de Chiapas. Chenalhó, Larráinzar y Chamula. Editorial Claves Latinoamericanas, México.

Pitarch Ramón, Pedro, 1996, Ch'ulel: Una etnografía de las almas tzeltales. Fondo de Cultura Económica, México.

Pozas Arciniega, Ricardo, 1977, Chamula. Instituto Nacional Indigenista, Colección Clásicos de la Antropología Mexicana n. I-II, México.

Robledo Hernández, Gabriela Patricia, 1987, «Disidencia y religión: Los expulsados de San Juan Chamula». Tesis de licenciatura. Escuela Nacional de Antropología e Historia, México.

Rus, Jan, 1982, La situación política en Chamula: Desarrollo y cambios actuales 19351975. Instituto de Asesoría Antropológica para la Región Maya, A. C., San Cristóbal de Las Casas, Chiapas.

1995a, «¿Guerra de castas según quién? Indios y ladinos en los sucesos de 1869». En Los rumbos de otra historia. Instituto de Investigaciones Filológicas-Universidad Nacional Autónoma de México/Centro de Investigaciones y Estudios Superiores en Antropología Social/Centro de Estudios Mexicanos y Centroamericanos-Universidad de Guadalajara, México.

1995b, «La comunidad Revolucionaria Institucional: la subversión del gobierno indígena en los altos de Chiapas, 1936-1968». En Los rumbos de otra historia, Instituto de Investigaciones Filológicas-Universidad Nacional Autónoma de México/Centro de Investigaciones y Estudios Superiores en Antropología Social/Centro de Estudios Mexicanos y Centroamericanos-Universidad de Guadalajara, México. 
Rus, Jan y Robert Wasserstrom, 1979, «Evangelización y control político: el Instituto Linguístico de Verano (ILV) en México». Revista Mexicana de Ciencias Políticas y Sociales, n. 97, Universidad Nacional Autónoma de México, México.

Ruz, Mario Humberto, 1982, Los legítimos hombres. Aproximación antropológica al grupo tojolabal, v. II. Centro de Estudios Mayas, Instituto de Investigaciones Filológicas, Universidad Nacional Autónoma de México, México.

Sánchez Carrillo, Óscar, 2007, «Cuerpo, ch’ulel y lab. Elementos de configuración de la persona tzeltal en Yajalón, Chiapas». En revista Pueblos y fronteras digital, n. 4, http://www.pueblosyfronteras.unam.mx, Programa de Investigaciones Multidisciplinarias sobre Mesoamérica y el Sureste, Instituto de Investigaciones Antropológicas, Universidad Nacional Autónoma de México, México.

Siverts, Henning, 1969, Oxchuc: una tribu maya de México. Instituto Indigenista Interamericano, México.

Toledo Tello, Sonia, 1996, Historia del movimiento indígena en Simojovel 1970-1989. Instituto de Estudios Indígenas, Universidad Autónoma de Chiapas, México.

Villa Rojas, Alfonso, 1990, Etnografía tzeltal de Chiapa. Modalidades de una cosmovisión prehispánica. Consejo Estatal para el Fomento de la Investigación y Difusión de la Cultura, Gobierno del estado de Chiapas, México.

Viqueira, Juan Pedro, 1987, «Cronotopología de una región rebelde. La construcción histórica de los espacios sociales en la Alcadía Mayor de Chiapas (1520-1720)». Tesis de doctorado. EHESS, París.

1995, «Los Altos de Chiapas: una introducción general». En Los Rumbos de Otra Historia. Instituto de Investigaciones Filológicas-Universidad Nacional Autónoma de 


\section{México/Centro de Investigaciones y Estudios Superiores en Antropología Social/Centro} de Estudios Mexicanos y Centroamericanos-Universidad de Guadalajara, México.

\section{Notas}

\footnotetext{
${ }^{1}$ Etnomedicina es un término genérico para hacer referencia a una medicina con base étnica, para el caso los sistemas etnomédicos mayas de Chamula, Chenalhó y Oxchuc.

${ }^{2}$ Baldiaje hace referencia al sistema de peones baldíos, que Toledo (1996: 77) caracteriza como: «...una especie de campesinos arrendatarios que vivían en las inmediaciones de las fincas y establecían contratos con los propietarios para trabajar algunas hectáreas de sus terrenos a cambio de proporcionar parte de la cosecha y/o trabajo gratuito».

${ }^{3}$ Los sistemas etnomédicos se constituyen a partir de la coherencia existente entre las representaciones particulares de una etnia, que se concretan en formas específicas de vivir, de conservar la salud, de enfermar y morir, y la coherencia entre estos conceptos y la atención a estos problemas, y atañen a grupos específicos. En este sentido Menéndez (2002: 70), señala: «...cada cultura produce su propio sistema médico, en términos de los particulares procesos simbólicos, sociales, psicosociales y/o económicopolíticos» que en dicho grupo tienen lugar.

${ }^{4}$ Distingo entre mestizos y ladinos de la siguiente manera: mestizos son aquellas personas que llevan sangre española e indígena pero que no viven en contacto cotidiano con población originaria, como es la mayoría de la población mexicana; ladinos son aquellos mestizos que viven en regiones donde predomina la población originaria, con la que interactúan cotidianamente.

${ }^{5}$ Para profundizar sobre la noción de lab, ver los trabajos de Pitarch 1996, Sánchez 2007, Page 2007 y 2010
}

Fecha de recepción: 4 de diciembre de 2009.

Fecha de aceptación: 15 de febrero de 2010. 